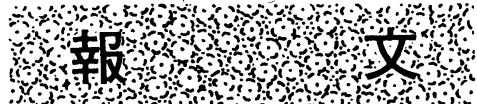

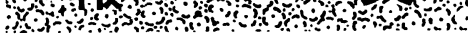

\title{
Inhibitory Effect of Hexametaphosphate on the Growth of Staphylococcus aureus ${ }^{* 1}$
}

(Received January 31, 1995)

\author{
Asao MatsuokA ${ }^{* 2}$, Masakazu Tsutsumi ${ }^{* 3}$ and Tadao Watanabe*4 \\ (*2Food Science and Human Nutrition, Kwassui Women's Junior College: \\ 1-50, Higashiyamate-machi, Nagasaki 850 , Japan; ${ }^{* 3}$ Faculty of \\ Agriculture, Ibaraki University: 3-21-1, Chuo, Ami-cho, \\ Inashiki-gun, Ibaraki 300-03, Japan; ${ }^{* 4}$ General \\ Education, Fukuoka Jogakuin College: \\ 2409-1, Ogohri, Ogohri-shi, \\ Fukuoka 838-01, Japan)
}

\begin{abstract}
A longer-chain polyphosphate exhibited a stronger antibacterial activity on Staphylococcus aureus, although other polyphosphates had about the same chelation values. Hexametaphosphate (HP), a long-chain polyphosphate, showed a minimum inhibitory concentration of $0.05 \%$ on the growth of $S$. aureus and had the strongest antibacterial activity among the polyphosphates examined. The chelation value and growth inhibitory effect of HP, which was hydrolyzed into lower-molecular-weight substances by heating, gradually decreased during heating, but the patterns of decrease differed. These findings suggest that the antibacterial effect of HP on $S$. aureus depends not only on its chelating ability, but also on its polymeric nature. At 0.05 to $1.0 \%$, HP exhibited no bactericidal action against $S$. aureus cells on incubation for $8 \mathrm{hr}$; its action was bacteriostatic. The viability of HP-treated cells gradually decreased on an agar plate containing $7.5 \%$ sodium chloride but not on a normal agar plate during treatment. This result suggests that $\mathrm{HP}$ acts on the cell membrane and decreases the salt tolerance of $S$. aureus. HP induced leakage of magnesium from cells into the medium, and increased the leakage of amino acids and low-molecular nucleic acid-related substances from cells into deionized water. The cells slowly leaked large amounts of magnesium and lowmolecular substances, a small amount of proteins and no nucleic acids during HP treatment for $6 \mathrm{hr}$. These results suggest a weak action of HP on the cell membrane and some damage to the cell membrane by HP. It was thus assumed that the antibacterial action of HP on S. aureus was caused by the loss of osmoregulation and selective permeability resulting from membrane damage, as well as a lowering of metabolic function arising from leakage of substrates.
\end{abstract}

Key words: polyphosphate; antibacterial activity; Staphylococcus aureus; hexametaphosphate; antibacterial effect; salt tolerance; leakage of substrate

\section{Introduction}

Polyphosphates having multifunctional properties have been used in many food products,

*1 Antibacterial action of hexametaphosphate on Staphylococcus aureus (Part 1). especially in milk, meat and fish products, for the purpose of improving tenderness, retaining moisture, emulsifying, buffering, etc. ${ }^{1-3)}$. The use of polyphosphates as food preservative agents is also possible, because they have antimicrobial activities ${ }^{4)}$, 5), and their effect on bacteria in foods has been reported by Kohl ${ }^{6)}$, Wagner and Busta ${ }^{7)}$ 
and Molins et $a l^{8-10)}$. Several studies suggest that gram-positive microorganisms are more sensitive to polyphosphates than gram-negative microorganisms ${ }^{11), 12)}$, though some gram-negative bacteria are sensitive ${ }^{13), 14)}$. Hexametaphosphate (HP), a long-chain polyphosphate, was ineffective against Escherichia coli, a gramnegative bacterium. However, the combined use of HP and other compounds was effective ${ }^{12), 15), 16)}$.

We have been working to elucidate the mode of action of HP to ensure its safety for use as a food preservative agent and have reported the action of HP on Bacillus subtilis ${ }^{17)}$, a grampositive food-decay bacterium, and $E$. coli ${ }^{18), 19}$. The target sites of HP on $B$. subtilis and E. coli were estimated to be the cell envelope and the outer membrane, respectively. Jen and Shelef ${ }^{20)}$ have reported that polyphosphates affect the growth of Staphylococcus aureus, a grampositive food-poisoning bacterium; sodium tripolyphosphate (STPP) produces less growth inhibition after heat sterilization, whereas HP retains most of its antibacterial activity after heat sterilization, and supplementation of the broth with $\mathrm{Mg}^{2+}$ is effective in overcoming inhibition by STPP restoring most of the growth. This restoration has been assumed to be related to chelation of STPP. However, the mode of antibacterial action of HP on S. aureus has not yet been confirmed. Accordingly, we have investigated the action of HP on S. aureus in detail. In this paper, we deal with the antibacterial activities of several polyphosphates on S. aureus, the effect of heating on chelation and growthinhibition by HP, the effect of HP on the survival of cells, the salt tolerance of HP-treated cells and the leakage of cell constituents during incubation with HP.

\section{Materials and Methods}

\section{Chemicals}

Sodium pyrophosphate, sodium tripolyphosphate, sodium tetrapolyphosphate, sodium hexametaphosphate (HP) and sodium ultrapolyphosphate were obtained from Polyphos Chemical Laboratories Co. Yeast extract was purchased from Japan Pharmacy Ltd., bacto tryptone from Difco Laboratories, and Ehrlich meat extract and polypepton from Kyokuto Pharma- ceutical Industries Co. Standard solutions of magnesium ion and calcium ion were purchased from Katayama Chemical Industries Co., Lleucine as a standard amino acid from Ajinomoto Co., bovine serum albumin as a standard protein from Sigma Chemical Ltd., and glucose and the other reagents from Wako Pure Chemical Industries Co.

\section{Bacterium and media}

Staphylococcus aureus IFO 3060 was obtained from the Institute for Fermentation, Osaka, Japan, and maintained on slants containing 1\% Ehrlich meat extract, 1\% polypepton, and 1.5\% agar, $\mathrm{pH}$ 6.8. TGP medium for tests contained $1 \%$ bacto tryptone, $0.25 \%$ yeast extract, $0.2 \%$ glucose, $0.2 \%$ potassium dihydrogen phosphate, and $0.3 \%$ dipotassium hydrogen phosphate, $\mathrm{pH}$ 7.0. TGP-agar medium contained $1.5 \%$ agar in TGP medium. All media were sterilized at $121^{\circ} \mathrm{C}$ for $20 \mathrm{~min}$.

\section{Inoculum preparation}

The bacterium on a slant was inoculated into $10 \mathrm{ml}$ of TGP medium in a normal test tube, and grown to the stationary phase at $30^{\circ} \mathrm{C}$ for $18 \mathrm{hr}$ with vigorous shaking. This culture was used in the test as an inoculum. For the preparation of inoculum used for the test of growth-inhibitory effect in Fig. 1, an L-shaped test tube was used and gentle reciprocal-shaking was conducted.

\section{Measurement of MIC on growth}

The inoculum (a stationary culture) was diluted with a sterile deionized water to give an optical density of 0.3 at $660 \mathrm{~nm}$ in a Photometer Model-1 (Tokyo Photoelectric Co.). The diluted inoculum $(0.5 \mathrm{ml})$ was added to TGP medium containing polyphosphate in a normal test tube, and the final $10 \mathrm{ml}$ culture was incubated for 24 hr at $30^{\circ} \mathrm{C}$ with vigorous shaking. Growth was evaluated by reading the optical density at 660 $\mathrm{nm}\left(\mathrm{OD}_{660}\right)$. MIC was determined by the two-fold dilution method.

MIC on growth of cells in the exponential phase was measured as follows: HP solution $(0.5$ $\mathrm{ml}$ ) was added to $9.5 \mathrm{ml}$ of exponential culture in a normal test tube, and the culture was further incubated under the same conditions. Growth was measured as described above at regular 
time intervals.

\section{Chelation and growth-inhibitory effect of heated $H P$}

HP solution (8\%; wt/vol) was heated in a boiling water bath, and cooled in an ice-water bath after 0.5 to $2.0 \mathrm{hr}$ of heating. The chelation value of HP was determined as described by Ishii et $a l .{ }^{21}$. The growth-inhibitory effect of HP was determined as follows. Heated or unheated HP solution was diluted to $5 \%$ (wt/vol) with deionized water. An aliquot of the dilute HP solution was added to a mid-exponential culture in an L-shaped test tube at a final concentration of $0.05 \%$, and the final $10 \mathrm{ml}$ culture was further incubated under the same conditions. Sterile deionized water was used in place of HP solution as a control. Growth was measured by reading the optical density at $660 \mathrm{~nm}\left(\mathrm{OD}_{660}\right)$ in a Shima$\mathrm{dzu}$ Spectronic $20 \mathrm{~A}$ Spectrophotometer after 10,20 and $30 \mathrm{~min}$ of incubation. Growth was directly proportional to incubation time up to $30 \mathrm{~min}$ in all cultures. The inhibitory effect was calculated.

\section{Survival of cells incubated with $H P$}

HP was added to an exponential culture and the culture was further incubated. After 2, 4, 6 and $8 \mathrm{hr}$ of incubation, viable counts were measured by plating serial dilutions of samples with a physiological saline solution on prepoured plates containing $20 \mathrm{ml}$ of TGP agar medium in $9-\mathrm{cm}$-petri dishes. Plates were incubated at $30^{\circ} \mathrm{C}$ and colonies were counted after $48 \mathrm{hr}$ of incubation.

\section{Measurement of magnesium and calcium in medium}

The culture was centrifuged at $2,000 \times \mathrm{g}$ for $10 \mathrm{~min}$, and the content of metal ions in the resultant supernatant was measured by reading the absorbance at $2852 \AA$ for magnesium and at $4226.7 \AA$ for calcium in an atomic absorption spectrophotometer (model NF-IB; Toshiba-Beckman Co.).

\section{HP treatment of $S$. aureus}

$S$. aureus, which was grown exponentially at $30^{\circ} \mathrm{C}$ with shaking after adding $10 \mathrm{ml}$ of inoculum (preculture) to $150 \mathrm{ml}$ of medium in a Saka- guchi flask, was harvested by centrifugation, washed twice with deionized water, and resuspended in water at $2 \times 10^{9}$ cells per ml $\left(\mathrm{OD}_{660}=\right.$ 0.3 in a Photometer Model-1). The cell suspension was incubated with or without $\mathrm{HP}$ at $30^{\circ} \mathrm{C}$ for 1 to $6 \mathrm{hr}$.

Measurement of salt tolerance of cells and leaked constituents

1) Salt tolerance: The suspension of treated cells was diluted and spread on a plate of TGPagar medium with or without $7.5 \%$ sodium chloride. Colonies were counted on the plate after incubation at $30^{\circ} \mathrm{C}$ for $48 \mathrm{hr}$.

2) Leaked constituents: The suspension of treated cells was centrifuged at $5,000 \times \mathrm{g}$ for 5 min, and the supernatant was obtained. Contents of amino acids, nucleic acid-related substances proteins and nucleic acids in the supernatant and the original suspension were determined (leaked amounts and total amounts, respectively).

Amino acid was determined by the ninhydrincolorimetric method ${ }^{22)}$ using L-leucine as a standard after neutralizing the cold 5\% trichloroacetic acid (TCA)-soluble fraction of the sample with sodium hydroxide solution.

Protein was determined by Lowry et al.'s method $^{23)}$ after preparation of the protein fraction. The preparation was carried out as follows. TCA was added to the sample at a concentration of $0.5 \%$, then the solution was heated in boiling water for $10 \mathrm{~min}$, cooled, and centrifuged. The precipitate was washed with $5 \%$ TCA, defatted with ethanol-ether solvent $(1: 1$, $\mathrm{v} / \mathrm{v}$ ), dried at room temperature under reduced pressure, dissolved in $0.1 \mathrm{~N}$ sodium hydroxide, and used for protein determination.

Nucleic acid-related substances (low-molecular-weight substances) and nucleic acid were determined as follows: Cold perchloric acid (PCA) was added to a cold sample at the concentration of $5 \%$, then the mixture was allowed to standfor $30 \mathrm{~min}$ in an ice-water bath and centrifuged. The supernatant (cold 5\% PCA-soluble fraction consisting of low-molecular-weight substances ${ }^{24)}$ ) and the precipitate (cold 5\% PCAinsoluble fraction consisting of high-molecularweight substances ${ }^{24}$ ) were obtained. Nucleic acid-related substances were determined by 
Table 1. Minimum Inhibitory Concentrations of Polyphosphates on the Growth of $S$. aureus

\begin{tabular}{lr}
\hline \hline Polyphosphate & MIC (\%) \\
\hline Pyrophosphate & $>0.80$ \\
Tripolyphosphate & 0.40 \\
Tetrapolyphosphate & 0.20 \\
Hexametaphosphate & 0.05 \\
Ultrapolyphosphate & 0.05 \\
\hline
\end{tabular}

Growth was evaluated after cultivation for 24 hr. MIC was determined by means of the two-fold dilution method.

reading the optical density at $260 \mathrm{~nm}\left(\mathrm{OD}_{260}\right)$ after dilution of the supernatant with deionized water. On the other hand, nucleic acids (RNA and DNA) were determined by measurement of $\mathrm{OD}_{260}$, after the precipitate had been washed with cold 5\% PCA, resuspended in 5\% PCA, heated for $15 \mathrm{~min}$ in a boiling water bath (nucleic acids were hydrolyzed and solubilized ${ }^{24)}$ ), cooled in an ice-water bath, and centrifuged, and the supernatant diluted with deionized water.

\section{Results and Discussion}

\section{Antibacterial activities of polyphosphates}

Hexametaphosphate (HP) shows a remarkable antibacterial effect on gram-positive bacteria ${ }^{12}$. However, the mechanism has not been elucidated. Therefore, the growth-inhibitory effect of HP on S. aureus was first examined.

Antibacterial activities of several polyphosphates on S. aureus were examined. MIC of the polyphosphates on growth are shown in Table 1. A longer-chain polyphosphate exhibited a stronger antibacterial activity on this bacterium. The strongest antibacterial activity was observed with very long-chain polyphosphates such as HP and ultrapolyphosphate (MIC $0.05 \%$ in each case). These results suggested that the chain-length of polyphosphate is important for the antibacterial effect on $S$. aureus.

Decrease in the chelation value and growthinhibitory effect of HP by heating

Jen and Shelef ${ }^{20)}$ have found that supplementation of broth with $\mathrm{Mg}^{2+}$ is effective in overcoming inhibition of $S$. aureus growth by sodium tripolyphosphate. We obtained the same

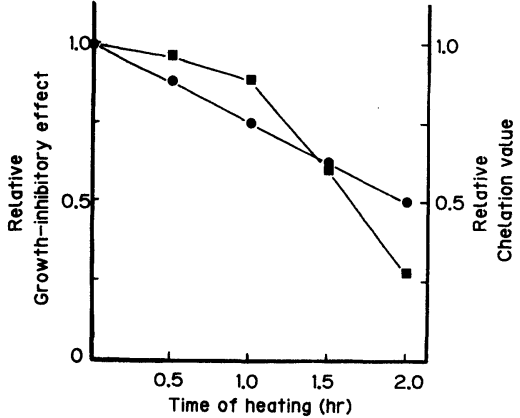

Fig. 1. Effect of heating on the chelation value and growth-inhibitory effect of HP

Chelation value (--) and growthinhibitory effect ( $-\square)$ were determined as seqestering capacity for $\mathrm{Ca}^{2+}$ per gram of HP and inhibitory effect of $0.05 \% \mathrm{HP}$ on growth rate, respectively. They are expressed as relative value to unheated $\mathrm{HP}$ in this figure. Chelation values were measured as described by Ishii et $a .^{21)}$.

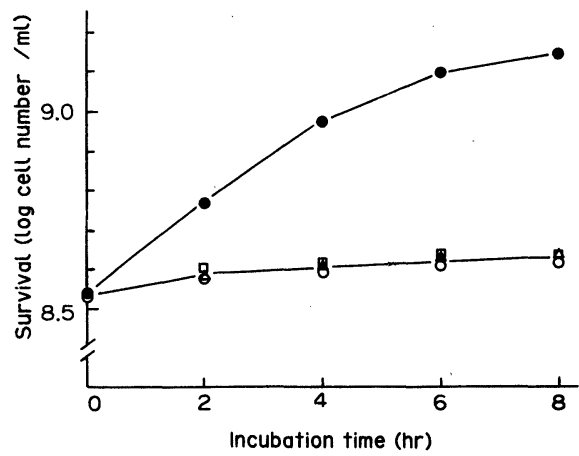

Fig. 2. Survival of $S$. aureus incubated with HP at various concentrations

HP was added to an exponential culture at the following final concentrations: $-\bigcirc, 0 ;-\square-, 0.05 ;-\triangle-, 0.10 ;-\bigcirc-$, $1.0 \%$. Incubation was continued under the same conditions, and viable counts were determined on TGP-agar medium as described in "Material and Methods". Cell numbers express the colony-forming units.

result with HP. Therefore, the growth inhibition may be related to the chelation properties of sodium tripolyphosphate and HP. To clarify that, the correlation between chelation and growth inhibition was examined by using HP hydrolyzed partially by heating.

As shown in Fig. 1, the chelation value and 
the growth-inhibitory effect of HP exhibited a linear decrease and a quadratic decrease, respectively, during heating. The relative value of the inhibitory effect was larger than that of chelation up to $c a .1 .5 \mathrm{hr}$ of heating, and then the situation was reversed. Thus, a significant difference between the two was observed. This showed that not only chelation properties but also other characteristics of HP were involved in the antibacterial effect. HP is converted into lower-molecular substances by hydrolysis during heating, so that high polymer residues decrease and lower-molecular substances increase $^{21)}$. The decrease of the high polymer residues is similar to that of the growth-
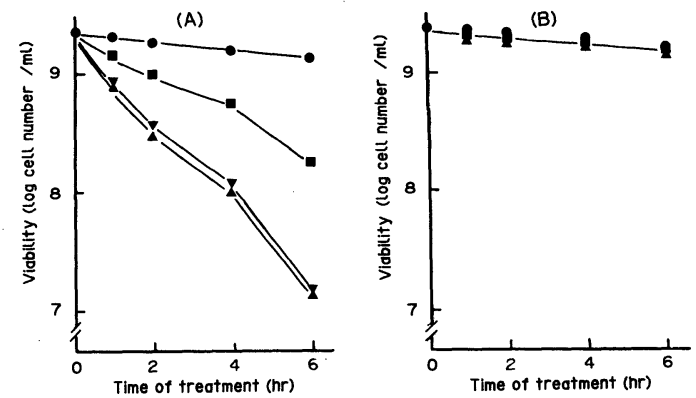

Fig. 3. Effect of $7.5 \% \mathrm{NaCl}$ on the viability of HP-treated S. aureus cells

Cells were treated with $0(-\mathbf{-}-), 0.01$ (一-), 0.05 (一- - ) and 1.0\% HP (- $-\mathbf{-}$ ). Treated cells were incubated on an agar plate containing 7.5\% NaCl-TGP medium (A) or TGP medium (B) at $30^{\circ} \mathrm{C}$ for $48 \mathrm{hr}$, and colonies were counted. Cell numbers express the colony-forming units.

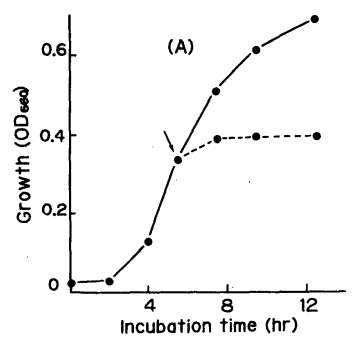

inhibitory effect of HP by heating. Furthermore, although the chelation values of polyphosphates are about the same ${ }^{2)}$, stronger antibacterial activity of longer-chain polyphosphate was observed in the above test (Table 1). These findings suggest that the marked antibacterial effect of HP depends on the high polymeric characteristics as well as on chelation. As suggested by Ishii $e t a l{ }^{21)}$, the antibacterial action of HP on S. aureus may be caused by its action on proteins in the cells, in particular cell-membrane proteins.

\section{Survival of cells incubated with HP}

The survival of $S$. aureus cells incubated with HP was examined in an exponential culture. The result is shown in Fig. 2. The number of surviving cell did not decline during incubation for $8 \mathrm{hr}$ with $0.05,0.10$ and $1.0 \% \mathrm{HP}$ arresting the growth of this bacterium in TGP medium. The result indicated that HP has no bactericidal effect, but rather a bacteriostatic effect on $S$. aureus in the medium.

\section{Salt tolerance of S. aureus cells treated with HP}

Allwood et al. ${ }^{25-27)}$ reported that the viability of mild-heat-treated S. aureus decreases on an agar plate containing $7.5 \%$ sodium chloride, but not on a normal agar plate, and surmised that the damage to the cell envelope, in particular cell-membrane damage, involved sensitivity to sodium chloride. The salt tolerance of $S$. aureus treated with HP was examined.

Viability of HP-treated cells on an agar plate

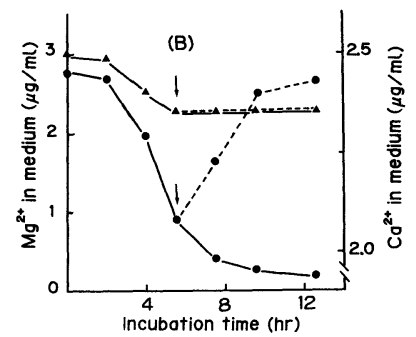

Fig. 4. Uptake of magnesium and calcium into $S$. aureus and leakage of them from the cells incubated with $0.05 \% \mathrm{HP}$

HP was added to an exponential culture at a final concentration of $0.05 \%$, and incubation was continued under the same conditions. Cell growth (A), and magnesium ( $\mathrm{B},--)$ ) and calcium $(\mathrm{B},-\mathbf{-}-)$ in the medium were measured at intervals. Arrows indicate the time of $\mathrm{HP}$ addition. A full line and a dotted line represent the absence and the presence of HP, respectively. 

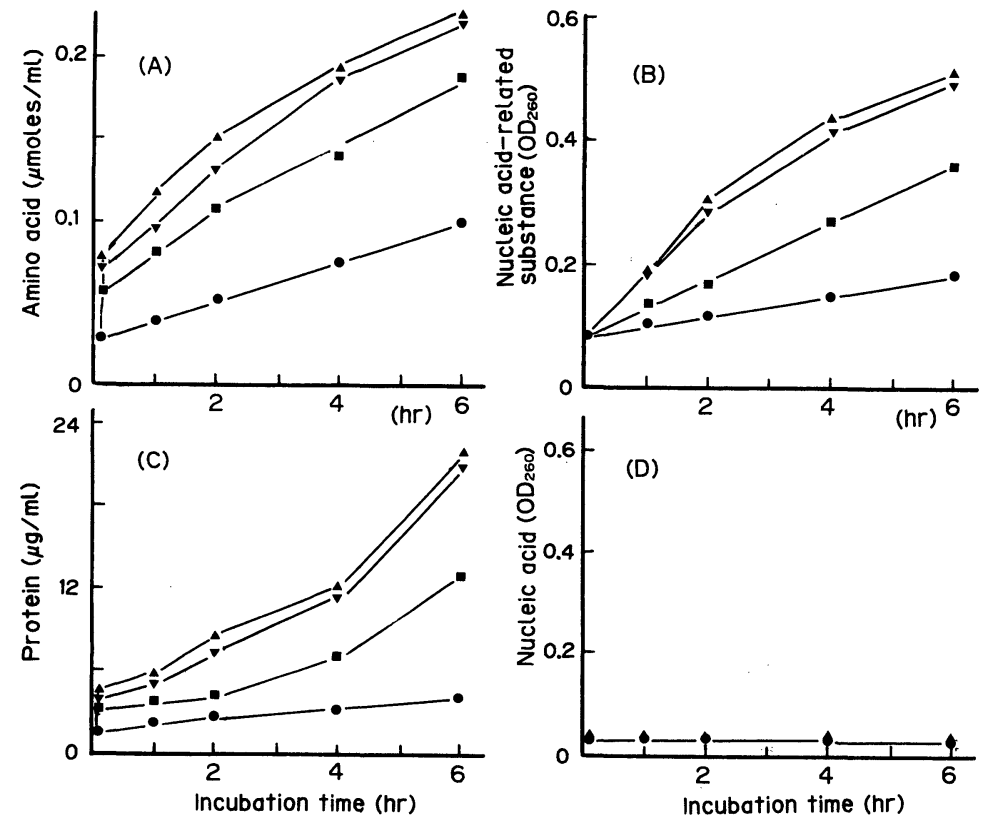

Fig. 5. Leakage of amino acids, nucleic acid-related substances, proteins and nucleic acids from $S$. aureus cells incubated with HP

Cell suspension was incubated with $0(-\bullet-), 0.01(-\mathbf{-}-), 0.05(-\boldsymbol{\nabla}-)$ and $0.10 \%$ HP ( $-\boldsymbol{\Delta}-)$ for 0 to $6 \mathrm{hr}$, and centrifuged. Amino acids (A), nucleic acid-related substances (B), proteins (C) and nucleic acids (D) were determined in the supernatant.

The cell suspension contained amino acids, nucleic acid-related substances, proteins and nucleic acids equivalent to $0.25 \mu \mathrm{mol} / \mathrm{ml}, \mathrm{OD}_{260}=0.64,283 \mu \mathrm{g} / \mathrm{ml}$ and $\mathrm{OD}_{260}=5.3$ as total contents, respectively.

with or without $7.5 \%$ sodium chloride is shown in Fig. 3. The cells treated without $\mathrm{HP}$ as a control showed no difference in viability between $7.5 \%$ sodium chloride-agar medium and a normal agar medium. On the other hand, the viability of HP-treated cells was decreased on a $7.5 \%$ sodium chloride-agar plate, but not on a normal agar plate. Based on this result, it is suggested that the salt tolerance of the cells was weakened by treatment with HP so that HPtreated cells had sublethal damage and became sensitive to $7.5 \%$ sodium chloride; it seems likely that HP has a weak action on the cell membrane of $S$. aureus.

Leakage of cell constituents in the presence of HP Generally, when membrane damage occurs there is leakage of cell constituents ${ }^{25), 27-29)}$. Therefore, the leakage of constituents was examined.

The uptake of magnesium and calcium in the growth phase, and the leakage of them from cells incubated with HP in TGP medium are shown in Fig. 4. Growth was accompanied with a remarkable magnesium uptake and small calcium uptake. Cells whose growth was arrested with HP leaked magnesium but not calcium. These results indicate a relationship between the antibacterial effect of HP and magnesium leakage. Magnesium is a component of the cell membrane of bacteria ${ }^{30)}$ and plays an important role in metabolic functions. Accordingly, it is surmised that HP acts on the cell membrane of $S$. aureus and reduces its metabolic functions. As shown in Fig. 5, HP stimulated a remarkable leakage of small-molecular substances such as amino acids and nucleic acid-related substances. The leakage was significant with $0.05 \% \mathrm{HP}$ treatment for $6 \mathrm{hr}$. A small amount of proteins but no nucleic acids leaked upon HP treatment. It is considered that the leaked proteins may be from the periplasmic space and membrane surface, because no nucleic acid leaked from the 
cytoplasm. The rate of constituent leakage induced by HP was slow in comparison to that induced by tripropyltin chloride ${ }^{31}$, which acts on membranes of bacteria ${ }^{32)}$ and reacts with phospholipid $^{33)}$, and sodium cholate ${ }^{34)}$, a kind of surface-active agent, which markedly affected the stability of protoplasts from S. aureus (data not shown). These results suggest a weak action of $\mathrm{HP}$ on the membrane and a disturbance of selective permeability. The finding that HP had no influence on the stability of the protoplasts of $S$. aureus (data not shown) also supported the idea that HP action on the cell membrane is weak. A study on leakage of constituents from the protoplasts by HP is in progress to clarify the antibacterial action of HP and its action on the cell membrane. Further, as the leakage pattern of proteins was similar to the pattern of decrease of viability on an agar plate with $7.5 \%$ sodium chloride in HP treatment, it was assumed that the decrease in salt tolerance by HP treatment might be a consequence of protein leakage.

We consider that the antibacterial action of $\mathrm{HP}$ on S. aureus is caused by the loss of osmoregulation and selective permeability resulting from membrane damage, as well as a lowering of metabolic function based on leakage of cell constituents.

\section{References}

1) Ishidate, M., ed.: “The 4 th ed. Shokuhintenkabutsu Kohteisho Kaisetsusho", p. B-890-901 and B922-927 (1979) Hirokawa Shoten Inc., Tokyo.

2) Hirata, A.: Shokuhin to Kagaku 9, 36-42 (1967).

3) Ogura, J.: ibid. 9, 57-59 (1967).

4) Ozawa, M., Nagaoka, T., Niigaki, S.: J. Food Hyg. Soc. Japan 4, 287-332 (1963).

5) Ozawa, M., Nagaoka, T., Niigaki, S.: ibid. 4, 333339 (1963).

6) Kohl, W. F.: Food Technol. 25, 102-110 (1971).

7) Wagner, M. K., Busta, F. F.: J. Food Sci. 48, 990993 (1983).

8) Molins, R. A., Kraft, A. A., Olson, D. G.: ibid. 50, 531-532 (1985).

9) Molins, R. A., Kraft, A. A., Walker, H. W., Rust, R. E., Olson, D. G., Merkenich, K.: ibid. 52, 46-49 (1987).

10) Molins, R. A., Kraft, A. A., Marcy, J. A.: ibid. 52, 513-514 (1987).

11) Molins, R. A., Kraft, A. A., Olson, D. G., Hotch- kiss, D. K.: ibid. 49, 948-949 (1984).

12) Tsutsumi, M., Nishimura, K., Yasui, K., Matsuoka, A., Watanabe, T.: J. Food Hyg. Soc. Japan 17, 273-275 (1976).

13) Elliott, R. P., Straka, R. P., Garibaldi, J. A.: Appl. Microbiol. 12, 517-522 (1964).

14) Zessin, K. G., Shelef, L. A.: J. Food Sci. 53, 669670 (1988).

15) Tsutsumi, M., Yasui, K., Isshiki, K., Watanabe, T.: J. Food Hyg. Soc. Japan 18, 341-345 (1977).

16) Suda, I., Miyayama, T., Suda, M., Tsutsumi, M., Watanabe, T.: ibid. 23. 302-307 (1982).

17) Isshiki, K., Tsutsumi, M., Nishimura, K., Watanabe, T.: ibid. 18, 335-340 (1977).

18) Tsutsumi, M., Yasui, K., Matsuoka, A., Watanabe, T.: ibid. 19, 190-194 (1978).

19) Suda, I., Miyayama, T., Matsuoka, A., Tsutsumi, M., Watanabe, T.: Nippon Nōgeikagaku Kaishi 55, 111-116 (1981)

20) Jen, C. M. C., Shelef, L. A.: Appl. Environ. Microbiol. 52, 842-846 (1986).

21) Ishii, S., Hirata, A., Watanabe, T.: Nippon Shokuhin Kogyo Gakkaishi 26, 279-286 (1979).

22) Nihon Kagakkai, ed.: Jikkenkagaku Kohza 23 , "Seibutsu Kagaku I", p. 126-130 (1957) Maruzen, Tokyo.

23) Lowry, O. H., Rosebrough, N. J., Farr, A. L., Randall, R. J.: J. Biol. Chem. 193, 265-275 (1951).

24) Andou, T., Terayama, H., Nishizawa, K., Yamakawa, T., ed.: "Seikagaku Kenkyuho II", p. 696697 (1967) Asakura Shoten, Tokyo.

Park, J. T., Hancock, R.: J. Gen. Microbiol. 22, 249-258 (1960).

25) Allwood, M. C., Russell, A. D.: J. Bacteriol. 95, 345-349 (1968)

26) Allwood, M. C., Russell, A. D.: J. Appl. Bacteriol. 32, 68-78 (1969).

27) Allwood, M. C., Hugo, W. B.: ibid. 34, 369-375 (1971).

28) Uehara, M.: Yakkyoku 35, 845-852 (1984)

29) Allwood, M. C.: Microbios 4, 93-96 (1971).

30) Hitcher, B. J., Egan, A. F.: Can. J. Microbiol. 23, 311-318 (1977).

31) Yamada, J., Tatsuguchi, K., Watanabe, T.: Agric. Biol. Chem. Jpn. 43, 125-130 (1979).

32) Yamada, J., Tatsuguchi, K., Watanabe, T.: ibid. 42, 1,867-1,870 (1978).

33) Yamada, J., Oishi, K., Tatsuguchi, K., Watanabe, T.: ibid. 43, 1,015-1020 (1979).

34) Tsutsumi, M., Narita, T., Matsuoka, A., Watanabe, T.: J. Food Hyg. Soc. Japan 21, 283-287 (1980). 